\title{
CIÊNCIA PARA TODOS?
}

SCIENCE FOR ALL?

\author{
¿CIENCIA PARA TODOS?
}

VIVIAN M. RUMJANEK*, WAGNER SEIXAS DA-SILVA

Programa de Pós-Graduação em Química Biológica - área de concentração em Educação, Gestão e Difusão em Biociências, Instituto de Bioquímica Médica Leopoldo de Meis, Universidade Federal do Rio de Janeiro, Rio de Janeiro, Brasil.

*vivian@ bioqmed.ufrj.br 


\title{
Resumo
}

O presente trabalho discute o atual conhecimento e interesse do jovem pela ciência, apresenta uma experiência metodológica de ensino bem sucedida por mais de três décadas, que pôde ser expandida para diferentes estados, com grande impacto social, envolvendo parcerias universidade-escola. Essa metodologia foi capaz de ser adaptada para um público surdo conhecido por sua dificuldade em se interessar e compreender a ciência. Afeta também os graduandos e pós-graduandos nas universidades envolvidas sensibilizando-os para a realidade brasileira.

Palavras-chave: Ensino para Surdos. Interação universidade-escola. Curso experimental.

\begin{abstract}
This paper discusses the current knowledge and interest of young people in Science, presents a teaching methodology experience that has been successful for over three decades, being expanded to different regions, with great social impact, involving university-school partnerships. This methodology was able to be adapted to a deaf audience known for its difficulty in understanding and becoming interested in science. It also affects undergraduates and postgraduates at the universities involved, making them aware of the Brazilian reality.
\end{abstract}

Keywords: Deaf Education. School-university interaction. Experimental course.

\section{Resumen}

Este documento analisa el conocimento actual y el interés de los jóvenes en la ciencia, presenta una experiencia de metodologia de enseñanza exitosa durante más de tres decadas, que podría ampliarse a diferentes estados, con gran impacto social, involucrando asociaciones universidad-escuela. Esta metodologia pudo adaptarse a um público sordo conocido por su dificultad para interesarse y compreender la ciencia. También afecta a los estudiantes de pregrado y posgrado en las universidades involucradas, haciéndolos conscientes de la realidad brasileña.

Palabras Clave: Enseñaza para Sordos. Interacción universidad-escuela. Curso experimental. 


\section{EDUCAÇÃO E INTERESSE POR CIÊNCIA}

A educação é o reflexo direto de uma época. Como tal, conceitos vão sendo modificados determinando a visão cultural do momento, ao mesmo tempo que a própria educação é determinada pelas ideias vigentes. A preparação para o "futuro", quando se desconhece o que será esse futuro, é de certa forma uma contradição e a educação passa a ser um reflexo do presente. Por outro lado, o avanço tecnológico e científico que ocorre desde a segunda metade do século 20, mostra claramente como ciência, tecnologia e educação estão interligados. E, interligados com um aspecto explícito que não era tão considerado anteriormente, isto é, que a inovação, resultando desses processos, gera royalties que por sua vez determinam de forma importante a economia. Como resultado, em todo mundo está havendo uma ênfase na área de Science, Technology, Engineering, Mathematics (STEM) na busca de atrair jovens para esse campo do conhecimento. Isso porque, desde o final do século 20 , vem sendo observado uma falta de engajamento público e de interesse entre os jovens por essa área (OSBORNE, SIMON, COLLINS, 2003; JENKINS, NELSON, 2005; LYONS, 2006; BARMBY, KIND, JONES, 2008). Esse declínio de interesse, aliado a importância econômica da área, faz com que vários estudos procurem compreender o fenômeno que envolve o fato de jovens serem usuários da tecnologia e ao mesmo tempo não se sentirem compelidos a compreender a base científica que deu origem a estes avanços. De forma semelhante, utilizam a tecnologia, mas não desenvolvem a capacidade crítica. Outro aspecto, que independe dos aspectos econômicos, e que evidencia a importância da compreensão mesmo que superficial da ciência, é o fato que esse conhecimento nos permite que exerçamos nossa cidadania em assuntos que nos afetam diretamente, permitindo decisões e participação em problemas como aquecimento global, vacinação, envenenamento por agrotóxicos etc., assim como discussões sobre como a ciência pode influenciar a nossa vida. Portanto, a "cultura" científica pode abordar diversos aspectos que irá variar dentro do objetivo pretendido (SMITH, GUNSTONE, 2009).

Mas a educação formal ocorre nas escolas, e é nelas que o interesse por ciência deveria ser despertado e estimulado, todavia talvez a forma de ensinar não tenha 
acompanhado o avanço tecnológico. Um estudo de Trundle e Saçkes (2012) sugere que crianças não são expostas de forma adequada à ciência, talvez porque professores de ensino fundamental não se considerem aptos para cobrir essa área de conhecimento (TILGNER, 1990). Buscando aproximar o jovem do conhecimento científico outras formas de aprendizado foram sendo desenvolvidas. As diferentes nuances encontram-se sob a definição geral de aprendizado ativo e existem evidências de que alunos que vivenciam esse processo obtém melhores notas e possuem um grau de aprovação maior do que aqueles que vivenciaram o ensino tradicional (FREEMAN et al. 2014). Além disso, alunos que vivenciaram ensino ativo de ciências através de questionamentos, mostraram no futuro atitudes mais positivas relativas à ciência (GIBSON, CHASE, 2002). Um estudo sobre o ensino de ciências na Suécia, Inglaterra e Austrália sugere que o impacto nesse estágio da vida também pode levar a um declínio na motivação em estudar ciência (LYONS, 2006).

Em crianças pequenas, o aprendizado e o papel da família podem ser determinantes para desenvolver nessas crianças o fascínio pela ciência (BONNETTE, CROWLEY, SCHUNN, 2019). No entanto, essa realidade pode criar um conflito. O aprendizado de ciências obtido através da escola, está na maioria das vezes, muito distante das atividades da vida diária. Existem estudos sugerindo, inclusive, que o interesse dos adolescentes não é mantido pelas atividades da escola (ANDERHAG et al, 2016). Mas é preciso considerar a limitação de muitos pais e familiares, principalmente aqueles em lares mais carentes, que não possuem eles mesmos uma proficiência científica, sendo incapazes de estabelecer uma relação entre o que fazem e os avanços científicos tecnológicos (OLORUNTEGBE, 2012). Certamente no Brasil a situação não é diferente, aumentando a distância para jovens de baixa renda.

\section{APRENDENDO CIÊNCIA COM QUEM FAZ CIÊNCIA}

O avanço tecnológico e científico brasileiro e a atual ênfase na inovação, significa que existe no nosso país a necessidade de indivíduos qualificados nas áreas da ciência e tecnologia. Entretanto, existe uma enorme barreira para atrair jovens para essa 
área. Os professores do ensino fundamental e médio normalmente fizeram licenciatura, que os permite ensinar, e fizeram essa opção sobre o bacharelado que pressupõe estar formando indivíduos para o mercado de trabalho (MARANDINO, 2003). Como resultado muitos professores não vivenciaram a investigação científica e, os métodos atuais de ensino ativo envolvendo questionamento, colaboração, solução de problemas, mão na massa etc. são vistos como técnicas pedagógicas para produzir um engajamento maior dos alunos, e não como uma forma integrada de agir e pensar como um cientista. Acrescente-se a isso a ausência de laboratórios em grande parte das escolas. Um método desenvolvido nos anos 70, e que potencialmente seria capaz de mostrar o processo da ciência foi o método da redescoberta (DEVONS, HARTMANN, 1970). Mas, aqui também, o que se fazia era copiar os passos experimentais do que já havia sido descoberto. Faltava uma das grandes características da ciência: curiosidade e questionamento. Também não existia a possibilidade do desconhecido ou de não acontecer como previsto.

Uma abordagem inovadora ocorreu na década de 1980, quando o Prof. Leopoldo de Meis, que era um cientista com inúmeras publicações relevantes na área de bioenergética e transporte de cálcio no tecido muscular (VICTORINO, 2019), iniciou o desenvolvimento de duas ações educacionais. Ele criou os Cursos Experimentais de Curta Duração (Curso de Férias) e o Programa de Jovens Talentosos para alunos de baixa renda.

O objetivo era mostrar aos alunos do ensino médio uma visão da ciência distinta daquela puramente informativa, ensinada nas escolas. Os cursos eram realizados na universidade com duração de uma semana e envolviam somente atividades práticas. Esses cursos iam muito além do conceito de "hands on" (mão na massa) onde um protocolo experimental é desenvolvido pelo aluno, e passa a adotar o conceito adicional de "minds on", onde, dentro de um determinado tema, o próprio aluno faz as perguntas em que está interessado e busca realizar experimentos para encontrar a resposta. Tudo isso realizado na universidade com grupos de professores e monitores (graduandos e pós-graduandos) que trabalham em ciência. É o conceito de aprender ciência fazendo ciência.

Os cursos são desenvolvidos de forma lúdica, integrando conhecimento e diversão, acontecem regularmente durante as férias escolares para professores e alunos do ensino médio e são em tempo integral por uma semana (40 horas). A metodologia se 
baseia no método científico e, como tal, envolve uma metodologia ativa, em que, dado um tema, são os próprios alunos, que divididos em pequenos grupos, fazem as perguntas, sugerem os experimentos, realizam os experimentos, discutem os resultados, criam hipóteses, apresentam seus resultados publicamente para os colegas e continuam a realizar novos experimentos até conseguirem encontrar um resultado que os satisfaça. Esta proposta oferece a oportunidade de aprendizado diferenciado em áreas das ciências naturais e da saúde. A equipe de monitores é treinada para não dar respostas, apenas ajudar os cursistas na execução de experimento proposta por eles.

O primeiro curso experimental de curta duração foi realizado em 1985. Em 1993, os cursos passaram a ser oferecidos para professores e licenciandos. Analisando o número total de alunos e professores cursistas ao longo dos anos (Figura 1), percebemos que a procura de jovens pelos cursos continua sendo muito grande.

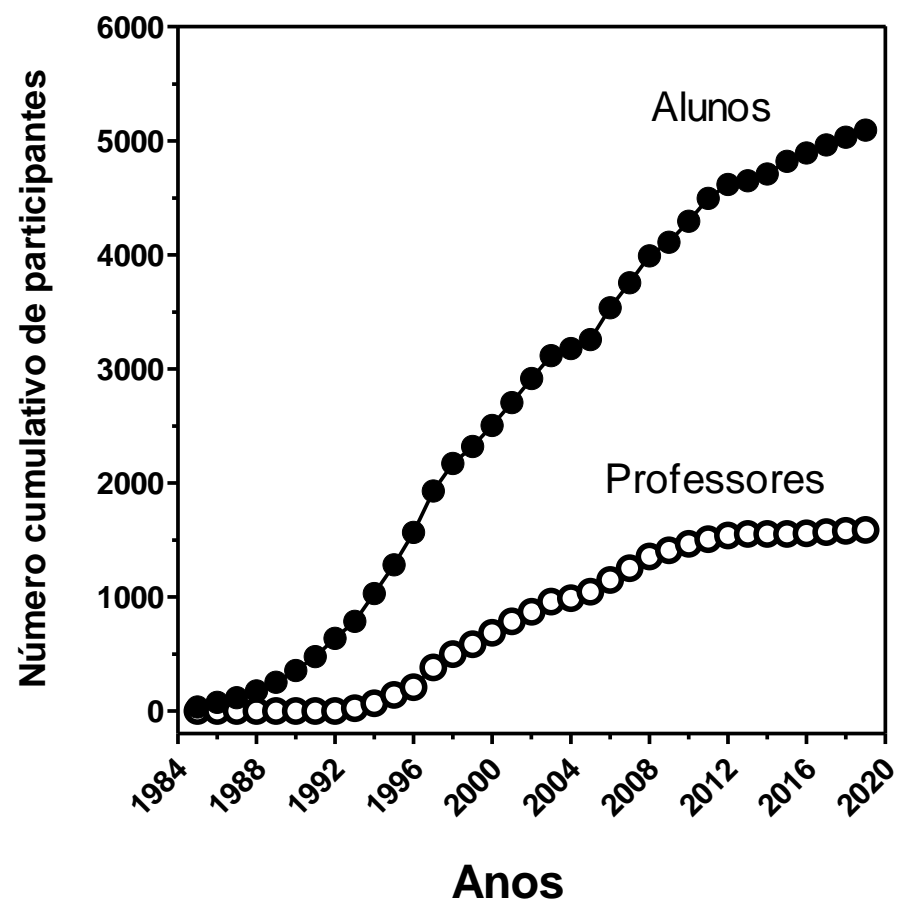

Figura 1: Número cumulativo de alunos e professores/licenciandos do ensino fundamental e médio que participaram dos Cursos de Férias na UFRJ ao longo dos anos. 
Os cursos são oferecidos regularmente nas férias de janeiro e julho desde 1985 quando foram oferecidos pela primeira vez. A oferta de cursos para professores e licenciandos teve início em 1993. O número de alunos é mostrado em círculos fechados e de professores em círculos abertos. A figura só inclui os participantes de cursos experimentais de um grupo da Universidade Federal do Rio de Janeiro (UFRJ) filiado a Rede Nacional de Educação e Ciência (RNEC).

Raramente vemos um projeto de interação universidade-escola que consegue manter suas atividades durante quase quatro décadas. No entanto, fazendo uma análise crítica, percebemos que a nossa capacidade de atrair professores para os cursos tem sido impactada. Uma justificativa apresentada pelos professores cursistas é que o período de férias é cada vez menor e existe uma demanda de planejamento do ano letivo que ocorre já nas férias dos alunos.

Destes cursos surgiu a segunda ação proposta por Meis que se tratava do oferecimento de estágios em seu laboratório para alunos do ensino médio, e de preferência de baixa renda (REGALADO, 2010). Na época, os estágios para alunos de escola era algo inovador, mas essa experiência ainda é valorizada nos grandes centros de pesquisa, mais de trinta anos depois (LESCAK et al. 2019), Meis possibilitou que conhecessem um laboratório de pesquisa e cientistas, convivessem com um ambiente científico e desmistificassem o que isso significava. Passando a considerar que também poderiam trabalhar em ciência. Por outro lado, ao colocar pós-graduandos orientando esses jovens, estava aproximando o futuro pesquisador da realidade brasileira. Sob a orientação de estudantes de pós-graduação, os estagiários se familiarizam com o trabalho científico e ajudam seus tutores no desenvolvimento de pesquisas. Além disso, os universitários acompanham o desempenho escolar dos estagiários, auxiliando-os em disciplinas em que apresentem dificuldade. Ao longo destes anos cerca de 150 jovens foram selecionados para estágios em laboratórios de bioquímica do Instituto de Bioquímica Médica Leopoldo de Meis UFRJ. A grande maioria (aproximadamente 90\%) ingressou na universidade e alguns se tornaram professores/pesquisadores da própria instituição. Uma descrição destas ações pode ser vista nos links (https://is.gd/uUNsEO) e (https://is.gd/k326YO). 
Esta proposta rapidamente se expandiu com apoio da agência Financiadora de Inovação e Pesquisa (FINEP) e da Coordenação de Aperfeiçoamento de Pessoal de Nível Superior (CAPES). A metodologia foi replicada em diversas universidades por docentes pesquisadores de diversas áreas do conhecimento associados a programas de pósgraduação, o que deu origem a Rede Nacional de Educação e Ciências: novos talentos da rede pública RNEC, que incorporou o nome do seu fundador após o seu falecimento passando a se chamar Rede Nacional Leopoldo de Meis de Educação e Ciências: novos talentos da rede pública. Um pequeno vídeo sobre a Rede Nacional de Educação e Ciência pode ser acessado pelo link (https://is.gd/QSIt8B).

Atualmente a RNEC é constituída por 34 grupos, vinculados a 21 instituições de ensino e pesquisa distribuídas em 12 estados da federação. Para manter o espírito do projeto e promover trocas de experiências, de materiais produzidos etc. é realizado anualmente um encontro que conta com palestrantes convidados e é aberto para o público.

\section{INFLUÊNCIA EM POLÍTICAS PÚBLICAS}

Atualmente ainda é preciso superar a definição restrita de que atividades de extensão sejam apenas assistencialismo e filantropia. Meis entendeu que podia intervir em questões sociais e oferecer soluções para os problemas do país além de sugerir novas políticas educacionais. Certamente podemos identificar que ao longo da trajetória da RNEC as ações iniciadas pelo Prof. Meis tiveram forte influência em políticas de financiamento para a divulgação científica, desmistificação da ciência e melhoria da qualidade de ensino de ciências.

Os estágios para alunos do ensino médio oferecidos por Meis, ainda na década de 80, influenciaram diversas agências de fomento que hoje oferecem bolsas para alunos do ensino médio.

Os impactos das atividades da RNEC serviram para incentivar a criação de políticas públicas como a criação do programa da CAPES "Jovens Talentos para a Ciência". 
Apesar de duas ações constituírem a espinha dorsal da RNEC: cursos experimentais de curta duração e estágios, várias outras atividades são desenvolvidas pela Rede, de acordo com a realidade de cada instituição, como a produção de materiais didáticos e paradidáticos diferenciados, peças de teatro, clube de ciências, olimpíadas científicas e projetos itinerantes, entre outros.

Estas ações contribuem para desenvolver nos jovens das escolas públicas a independência com relação ao aprendizado e, consequentemente, a uma melhor formação para o mercado de trabalho e exercício da cidadania, além de permitir que ele desenvolva o talento para a pesquisa.

Passados 34 anos desde o oferecimento do primeiro curso de férias, podemos perceber que as ações propostas inicialmente expandiram os objetivos. Uma breve reflexão nos permite identificar que indiretamente talvez a RNEC tenha contribuído para um amplo espectro de impactos que, no entanto são mais difíceis de serem quantificados (tabela 1).

Tabela 1 - Percepção de contribuições indiretas das ações da RNEC, mas que são de difícil quantificação.

Impactos Contribuições

- Metodologias educativas nas atividades experimentais de curta duração

Tecnológico

- Produtos educativos áudio visuais (CDs e DVDs)

- Publicação de materiais educativos: Livros, álbuns ilustrados e fascículos de atividades.

- Kits e jogos educativos.

- Capacitação de jovens para rápidas adaptações a inovações contínuas do mercado de trabalho

Econômico

- Aperfeiçoamento de professores que já atuam no mercado de trabalho para trabalharem com novas metodologias.

- Conscientização de pós-graduandos e pesquisadores frente à responsabilidade social como educadores 
Social - Melhoria da autoestima e do nível de consciência de cidadania de alunos e professores das escolas públicas e das universidades atingidas pelo projeto

- Melhoria da qualidade do ensino de ciências nas escolas públicas

- Atividades experimentais de curta duração voltadas para a

Ambiental preservação do meio ambiente.

- Promover a utilização de material reciclável nas escolas públicas.

\section{CIÊNCIA PARA TODOS?}

Em 1985 foi instituído pela American Association for the Advancement of Science o movimento Science for All Americans (FENSHAM, 1985) procurando desenvolver o que se chamava "alfabetização científica". Para tal buscava, através de educação formal e informal, produzir na sociedade uma compreensão de como o conhecimento científico é gerado, os processos que lhe dão origem, além do contexto em que ocorre; aumentando também a percepção do que é ciência e quem são os cientistas (GLAZE, 2018). Infelizmente, vários anos depois ainda há, mesmo nos EUA (SMITH, GUNSTONE, 2009), muitas concepções errôneas sobre o papel da ciência. Concepções essas que podem afastar jovens da busca do conhecimento científico.

Mas será possível a Ciência para Todos? Existem evidências de que meninas são menos encorajadas a se interessar por ciência comparadas com meninos (TENENBAUM, LEAPER, 2003) e o mesmo é verdadeiro para crianças negras nos Estados Unidos que possuem poucas expectativas e até mesmo reações negativas com relação à ciência (ATWATER, 2000; ARCHER, DEWITT, OSBORNE, 2015).

No Brasil, como discutido acima, indivíduos de baixa renda tendem a possuir menos acesso a cultura científica. No momento em que se permite a realização de conexões entre o que estão aprendendo no curso de ciências e suas vidas, se promove também o interesse pela ciência e o aumento de expectativas (HULLEMAN, HARACKIEWICZ, 2009). O mesmo é verdadeiro quando as indagações e busca por 
soluções partem dos próprios estudantes.

No Brasil, o número mais restrito de vagas nas universidades públicas acrescido a uma menor preparação para os exames seletivos, tornava muito remota a possibilidade de ingresso desse público de baixa renda nessas universidades. Esse quadro foi aos poucos se modificando com a criação de cotas para as universidades.

O Brasil é um dos países do mundo com o mais avançado conjunto de leis sobre acessibilidade, apesar da dificuldade em encontrá-las implementadas. Da mesma forma com que foram criadas cotas baseadas na renda, raça e formação prévia em escola pública, a legislação brasileira sofreu modificações para permitir melhores oportunidades para pessoas com deficiência incluindo a comunidade surda. Como resultado da Lei 13 409/2016, políticas públicas têm garantido que pessoas com deficiência tenham acesso a cursos universitários e existe uma política de reserva de vagas para esse público.

\section{A CIÊNCIA E OS SURDOS}

No nosso país, de uma população de 196,8 milhões em 2010, 9,7 milhões apresentam dificuldades auditivas (5,1\% da população em geral), não sendo possível, no entanto, estabelecermos quantos apresentam surdez. Indivíduos com deficiência auditiva diferem quanto ao grau de surdez, a idade em que ficaram surdos e se sua comunicação é através da língua de sinais ou da língua de seu país.

Mesmo entre os indivíduos surdos severos/profundos a diversidade é enorme: existem os surdos sinalizantes, que utilizam para se comunicar a língua de sinais (no caso do Brasil, a Libras). Entre eles existem aqueles que conseguem ler e escrever, mas que não é a maioria. Existem também surdos "oralizados" que fazem leitura labial e falam e, neste grupo alguns não conhecem Libras, mas lêem e escrevem.

Acrescente-se que o país adotou em diversos momentos, diferentes políticas educativas (DIAS et al, 2014), sendo que atualmente adota-se o bilinguismo, em que a língua de sinais é considerada a primeira língua (L1) do surdo e deveria ser sua língua de instrução, e a língua portuguesa escrita (L2), deveria ser sua segunda língua. A língua 
portuguesa deveria ser ensinada quando o indivíduo já possuísse uma boa proficiência na língua de sinais. No entanto, como a maioria dos surdos são filhos de pais ouvintes, muitas dessas crianças não possuem língua alguma ao ingressarem na escola, que por sua vez não sabe se estruturar para receber o surdo adequadamente dentro das particularidades que ele apresenta. É uma situação que difere bastante do bilinguismo com crianças imigrantes, que possuem uma L1 bem consolidada que compartilham com seus familiares, e que naturalmente, a partir de um conhecimento linguístico, passam a conhecer uma segunda língua (LEITE, 2008).

Devido às dificuldades linguísticas encontradas, muitos dos surdos sinalizantes possuem baixa escolaridade e, ao não conseguirem obter uma qualificação, acabam deixando precocemente o emprego ou são sub-empregados, não sendo levada em consideração sua capacidade intelectual. Os próprios surdos possuem baixa auto-estima e o próprio sistema escolar não espera muito deles.

Muito poucos prosseguem seus estudos até o ensino superior e, segundo dados de 2015, o número total de alunos surdos matriculados em todas as universidades brasileiras era 1 650. Desses, somente uma minoria procurava cursos ligados à ciência. Apesar de a proporção ser bem diferente, uma situação semelhante é encontrada nos EUA onde $3,6 \%$ da população apresenta dificuldade auditiva e os surdos representam $0,8 \%$ dos alunos de graduação. No entanto, na Gallaudet University, uma universidade só para surdos, apenas 5\% dos alunos de graduação se interessam por áreas científicas (GOMARLLY, 2017).

As discussões relacionadas ao ensino de estudantes surdos no Brasil são principalmente focadas em problemas da língua e da dificuldade comunicativa. Poucas abordam outras questões como, por exemplo, o ensino de ciência para este grupo. Durante a observação dos resultados positivos recorrentes obtidos pela metodologia experimental desenvolvida pelo Prof. de Meis, a metodologia foi adaptada para ser utilizada em cursos de ciências de curta duração para alunos surdos do ensino médio, dando origem em 2005, na UFRJ, ao Projeto Surdo UFRJ ${ }^{1}$ (BARRAL, PINTO-SILVA, RUMJANEK, 2017)

\footnotetext{
${ }^{1}$ Disponível em: 〈https://is.gd/MWblih >. Acesso em: 16 ago. 2019.
} 
através do qual já foram oferecidos cerca de 30 cursos em 14 anos (MARTINS, 2011; PINTO-SILVA, MARTINS, RUMJANEK, 2013). Todos os anos há uma grande procura pelos cursos sendo maior a procura do que as vagas que podemos ofertar. A experiência foi expandida para o Nordeste em 2007 quando foi criado o Surdo Cientista na Universidade Federal da Paraíba (UFPB) em João Pessoa, pela Profa. Sandra RodriguesMascarenhas, mostrando que a metodologia pode ser replicada com sucesso e, desde então 16 cursos já foram oferecidos.

Utilizando-se a mesma metodologia também foi possível oferecer em uma escola especial para surdos, o Instituto Nacional de Educação de Surdos (INES), o ensino de ciências para crianças surdas do primeiro segmento do curso fundamental (FLORES, RUMJANEK, 2015).

Uma outra possibilidade testada foi a de oferecer para o ensino médio, um curso cobrindo todos os pontos mais importantes da área de biociências. O curso diário, sequencial, com mais de $900 \mathrm{~h}$ de duração, foi realizado na UFRJ, e as diferentes áreas foram sendo abordadas experimentalmente, sem aulas teóricas, baseadas totalmente no questionamento dos alunos (PINTO DA SILVA, 2013). Esse curso foi extremamente bem sucedido e não temos conhecimento de nada semelhante oferecido a surdos ou ouvintes. Além do interesse por ciência, os alunos que cursaram conseguiam ensinar conceitos científicos para outros alunos surdos e conseguiram realizar experimentos em outros laboratórios da universidade. No National Technical Institute for the Deaf (em Rochester) eles possuem um curso de um ou dois anos, eminentemente prático, que forma estudantes surdos para a área científica, mas difere do que foi realizado na UFRJ pois existe uma programação prévia de assuntos e abordagens, isto é, as aulas não partem do questionamento dos alunos surdos (PAGANO, ROSS, O’NEIL, 2012).

Um ponto que necessita ser esclarecido é a ideia, comum a todos os que não convivem com surdos, de que a presença de um tradutor/intérprete de Libras em sala de aula é capaz de resolver o problema do ensino de surdos. Isso é claramente uma simplificação e, no caso do ensino de ciências, era uma impossibilidade na época em que se criou o Projeto Surdos. O primeiro fator verificado foi falta de termos técnicos científicos em Libras, um aspecto também descrito em outros países (LANG et al, 2007). 
Iniciou-se então o processo de desenvolvimento de sinais na área de ciências. Ao vivenciarem um assunto através de experimentos e visualizações surgem alguns sinais espontâneos, icônicos, entre os alunos surdos. Esses sinais são anotados, discutidos em equipe, modificados ou não, testados com outro grupo de alunos surdos e, obtendo-se aceitação, são filmados e distribuídos sob a forma de vídeos e DVDs, para serem utilizados rotineiramente. A organização dos novos sinais é temática e parte de um assunto vivenciado pelos surdos, dessa forma já foram produzidos fascículos com sinais sobre Sangue (e circulação sanguínea), Sistema Imune, Células, Fertilização e Embriogênese, Biologia de Mosquitos e no momento estamos finalizando Microorganismos (RUMJANEK, 2011; BARRAL, PINTO-SILVA, RUMJANEK, 2012; RUMJANEK, 2016). Apesar de vários sinais já terem sido desenvolvidos, trata-se de um processo moroso e avaliou-se a possibilidade da apropriação de alguns empréstimos linguísticos de termos científicos em British Sign Language (BSL). O grupo do Scottish Sensory Centre (SSC), ligado à Universidade de Edimburgo, possui um glossário científico bastante completo em $\mathrm{BSL}^{2}$, realizado sob a coordenação de Rachel O’Neill, e uma parceria com o grupo permitiu a avaliação de alguns sinais no Brasil (BARRAL, RUMJANEK, 2018). Tendo sido demonstrada a viabilidade da utilização de alguns deles.

A ausência de sinais é uma dificuldade para os intérpretes/tradutores educacionais que variam em seu nível de competência linguística e no desconhecimento da área científica e isso não foi só observado no Brasil (SCHICK, WILLIAMS, KUPERMINTZ, 2006; RUMJANEK, 2011; GROOMS, 2015; RIEGER, 2016). Nesse caso, se o sinal não existe e se o intérprete desconhece ciência, ele não será capaz de transmitir uma informação correta.

Outro ponto a ser destacado é que a barreira comunicativa do surdo faz com que fique desprovido de informação em vários contextos. Temas gerais apesar de chegarem aos surdos, podem ser insuficientes ou estar deturpados (JOSEPH, SAWYER, DESMOND 1995; SCHIAFFINO, RUMJANEK, 2012; ALMEIDA, SCHIAFFINO, RUMJANEK, 2014). Como resultado da necessidade de criar instrumentos que vencessem essa barreira, Jurberg produziu uma série de vídeos de animação curtos sobre

\footnotetext{
${ }^{2}$ Disponível em: <https://is.gd/XLoupg >. Acesso em: 20 jul. 2019.
} 
prevenção de doenças, que servissem igualmente a surdos e ouvintes. Os vídeos, semelhante ao que ocorre nos cursos, visam despertar o interesse e perguntas, ao invés de “ensinar" sobre o assunto (JURBERG et al, 2013).

Considerando-se que a educação formal ocorre nas escolas, a colaboração entre a escola e a universidade abre portas tanto para alunos regulares como para alunos surdos. Os alunos deste último grupo encontram-se espalhados na rede pública de ensino e, por serem poucos por escola, dificilmente estão na mesma classe, sentem-se isolados e não compartilham ideias e opiniões. A vinda aos cursos para alunos surdos na universidade, permite não só aprender ciência, penetrar em um mundo antes inatingível, como encontrar outros surdos, e pela primeira vez argumentar sobre suas opiniões e ideias. Ao final do curso, ainda mais importante que seu aprendizado científico, foi verificar que todos os alunos desenvolveram uma atitude muito positiva em relação à ciência. Este é o primeiro passo para se mostrarem realmente interessados no assunto.

\section{CONCLUSÕES}

Quando se busca uma estratégia educacional certas características são fundamentais: a metodologia precisa funcionar, precisa ser capaz de ser expandida e replicada em diversas instituições, precisa, também, ter a capacidade de ser adaptada a outras condições sem perder sua capacidade funcional. A experiência de aprender ciência com quem faz ciência, como idealizado pelo Prof. Leopoldo de Meis, cobre todos esses quesitos e vem sendo utilizada há mais de 30 anos. Mostra também a importância do diálogo entre a escola e a universidade. Apresenta aos pós-graduandos a possibilidade de conhecer mais profundamente a realidade social dos alunos de escolas públicas que almejam um dia entrar na universidade e participar do processo de produzir ciência. Foi capaz de ser expandida para diversos estados brasileiros e replicada em diferentes universidades por docentes pesquisadores de diversas áreas do conhecimento. E, acima de tudo, mostrou-se capaz de ser adaptada para um público com deficiência conhecido pela sua dificuldade em se interessar e compreender a ciência, o público surdo. 


\section{REFERÊNCIAS}

ALMEIDA, R.C.N.; SCHIAFFINO, R.S.; RUMJANEK, V.M. Access and comprehension of information by profound deaf youngsters in Brazil. Journal of Media and Communication Studies, v. 6, n. 11, p. 174 - 178, 2014.

ANDERHAG, P.; WICKMAN, P.; BERGQVIST, K.; JAKOBSON, B.; HAMZA, K. M.; SALJO, R. Why Do Secondary School Students Lose Their Interest in Science? Or Does it Never Emerge? A Possible and Overlooked Explanation. Science Education, v. 100, p. 791-813, 2016.

ARCHER, L.; DEWITT, J.; OSBORNE, J. Is science for us? Black students' and parents' views of science and science careers. Science Education, v. 99, n. 2, p. 199$237,2015$.

ATWATER, M.M. Females in Science education: White is the norm and class, language, life style and religion are non-issues. Journal of Research in Science Teaching, v. 37, n. 4, p. 386-387, 2000.

BARMBY, P.; KIND, P.M.; JONES, K. Examining Changing Attitudes in Secondary School Science. International Journal of Science Education, v. 30, n. 8, p. 10751093, 2008.

BARRAL, J., PINTO-SILVA, F.E., RUMJANEK, V.M. Comunicando Ciência com as Mãos. Ciência Hoje, v. 296, p. 26-31, 2012.

BARRAL, J.; PINTO-SILVA, F.E.; RUMJANEK, V.M. Vendo e Aprendendo. In: LETRAMENTO VISUAL E SURDEZ. Tatiana Bolivar Lebedeff (Org.). Rio de Janeiro: Wak Editora, 2017.

BARRAL, J.; RUMJANEK, V.M. Empréstimos linguísticos para sinais científicos na área de biociências. (INES) Revista Espaço, v. 49, p. 55-70, 2018.

BONNETTE, R.N.; CROWLEY, K.; SCHUNN, C.D. Falling in love and staying in love with science: ongoing informal science experiences support fascination for all children. International Journal of Science Education, v. 41, n. 12, p. 16261643, 2019.

DEVONS, S.; HARTMANN, L. A history-of-physics laboratory. Physics today, v. 2, p. 44-49, 1970.

DIAS, L.; MARIANI, R.; DELOU, C.M.C.; WINAGRASKI, E.; CARVALHO, H.S.; CASTRO, H.C. Deafness and the Educational Rights: A Brief Review through a Brazilian Perspective. Creative Education, v. 5, p. 491-500, 2014.

FENSHAM, P.J. Science for all: A reflective essay. Journal of Curriculum Studies, 17:4, 415-435, 1985. 
FLORES, A.C.F.; RUMJANEK, V.M. Teaching science to elementary school Deaf children in Brazil. Creative Education, v. 6, p.2 127-2135, 2015.

FREEMAN, S.; EDDY, S.L.; MCDONOUGH, M.; SMITH, M.K., OKOROAFOR, N.; JORDT, H.; WENDEROTH, M.P. Active Learning Increases Student Performance in Science, Engineering, and Mathematics. Proceedings of the National Academy of Sciences of the United States of America, v. 111, p. 8410-8415, 2014.

GLAZE, A.L. Teaching and learning science in the 21st century: Challenging critical assumptions in post-secondary science. Education Sciences, v. 8, n. 1, 12, 2018.

GIBSON, H.L.; CHASE, C. Longitudinal Impact of an Inquiry-Based Science Program on Middle School Students' Attitudes Toward Science. Science Education, v. 86, n. 5, p. $693-705,2002$.

GORMALLY, C. Deaf, Hard-of-Hearing, and Hearing Signing Undergraduates' Attitudes toward Science in Inquiry-Based Biology Laboratory Classes. CBE Life Sciences Education, v. 16, n. 1, pii: ar6., 2017.

GROOMS, C. Interpreter competencies in Science, technology, engineering, and mathematics as identified by deaf professionals. Oregon: Western Oregon University, 2015 .

HULLEMAN, C.S.; HARACKIEWICZ, J.M. Promoting Interest and Performance in High School Science Classes. Science, v. 326, p. 1410-1412, 2009.

JENKINS, E.W.; NELSON, N.W. Important but not for me: students' attitudes towards secondary school science in England. Research in Science \& Technological Education, v. 23, n. 1, p. 41-57, 2005.

JOSEPH, J.M.; SAWYER, R.; DESMOND, S. Sexual knowledge, behavior and sources of information among deaf and hard of hearing college students. American Annals of the Deaf, v. 140, n. 4, p. 338-45, 1995.

JURBERG, C.; VERJOVSKY, M.; MACHADO, G.; RUMJANEK, V.M. Overcoming barriers: The development of na animated filmo $n$ human papiloma vírus (HPV) for deaf and hearing students. Scholarly Journal of Scientific Research and Essay (SJSRE), v. 2, n. 2, p. 27-23, 2013.

KISIEL, J. Understanding elementary teacher motivations for science fieldtrips. Science Education, v. 89, n. 6, p. 936-955, 2005.

LANG, H.G.; HUPPER, M.L.; MONTE, D.A.; BROWN, S.W.; BABB, I.; SCHEIFELE, P.M. A study of technical signs in science: implications for lexical database development. Journal of Deaf Studies and Deaf Education, v. 12, n. 1, p. 65-79, 2007. 
LEITE, T DE A. Língua, Identidade e Educação de Surdos. Ponto Urbe. 2008. DOI : 10.4000/pontourbe.1912

LESCAK, E.A.; O’NEILL, K.M.; COLLU, G.M.; DAS, S. Ten simple rules for providing a meaningful research experience to high school students. PloS

Computational Biology, v. 15, n. 4, p. 1-7, 2019.

LYONS, T. Different Countries, Same Science Classes: Students' experiences of school science in their own words. International Journal of Science Education, v. 28, n. 6, p. 591-613, 2006.

MARANDINO, M. A prática de ensino nas licenciaturas e a pesquisa em ensino de ciências: Questões atuais. Caderno Brasileiro de Ensino de Física, v. 20, n. 2, p. 168193, 2003.

\section{MARTINS, P.R.S. Adaptação do Ensino de Ciências para Jovens Surdos e} Avaliação de Estágios em Laboratório. 2011. Dissertação (Mestrado) - Química Biológica, Universidade Federal do Rio de Janeiro, Rio de Janeiro.

OLORUNTEGBE, Kunle Oke; ADAKOLE, Ikpe. Would Science Background be a Factor in Parents Helping Students Establish a Match between School Science and Home Activities?. Studies on Home and Community Science, v. 4, n. 2, p. 91-98, 2010 .

OSBORNE, J.A.; SIMON, S.B.; COLLINS, S. Attitudes towards Science: A review of the literature and its implications. International Journal of Science Education, v. 25, n. 9, p. 1049-1079, 2003.

PAGANO, T.; ROSS, A.D.; O’NEILL, A. A Program Like Any Other...Like None Other: Sustaining a Laboratory Science Technology Program for Deaf and HardofHearing Students. Journal of Science Education for Students with Disabilities, v. 15, n. $1,2011 / 2012$.

PINTO DA SILVA, F.E. Estudo, Capacitação e Ensino de Ciências para Jovens Surdos. 2013.Tese (Doutorado) - Química Biológica, Universidade Federal do Rio de Janeiro, Rio de Janeiro.

PINTO-SILVA, F.E.; MARTINS, P.R.S.; RUMJANEK, V.M. Rousing interest in science among secondary school deaf students. Scholarly Journal of Scientific Research and Essay (SJSRE), v. 2, n. 7, p. 104-108, 2013.

REGALADO A. Science in Brazil. Brazilian science: riding a gusher. Science. v. 330, p. 1306-1312, 2010.

RIEGER, C.P.E. A formação do intérprete de Libras para o ensino de Ciências: lacunas refletidas na atuação do TILS em sala de aula. 2016. Dissertação (Mestrado) - 
Programa de Pós-Graduação em Ensino, Universidade Estadual do Oeste do Paraná, Paraná.

RUMJANEK, J.B.D. Novos sinais para a Ciência: Desenvolvimento de um glossário científico em Libras. 2011. Dissertação (Mestrado) - Química Biológica, Universidade Federal do Rio de Janeiro, Rio de Janeiro.

RUMJANEK, J.B.D. Admirável Mundo Novo: A Ciência e o Surdo. 2016. Tese (Doutorado em Química Biológica), Universidade Federal do Rio de Janeiro, Rio de Janeiro.

SCHIAFFINO, R.S.; RUMJANEK, V.M. A divulgação Científica é surda aos surdos? Como o acesso ao conhecimento informal interfere na formação do conhecimento científico da população surda. Revista Tempo Brasileiro, v. 188, p. 79-96, 2012.

SCHICK, B.; WILLIAMS, K.; KUPERMINTZ, H. Look who's being left behind: educational Interprete,rs and access to education for deaf and hard-of-hearing students. Journal of Deaf Studies and Deaf Education, v. 11, n. 1, p. 3-20, 2006.

SMITH, D.V.; GUNSTONE, R.F. Science Curriculum in the Market Liberal Society of the Twenty-first Century: 'Re-visioning' the Idea of Science for All. Research in Science Education, v. 39, n. 1, p. 1-16, 2009.

TENENBAUM, H.R.; LEAPER, C. Parent-child conversations about science: the socialization of gender inequities? Developmental Psychology, v. 39, n. 1, p. 34-47, 2003.

TILGNER, P.J. Avoiding Science in Elementary School. Science Education, 74, 421431, 1990.

TRUNDLE, K.C.; SAÇKES, M. Ch.12: Science and Early Education. In: R. C. PIANTA, W. S. BARNETT, \& L. M. JUSTICE (EDS.), Handbook of Early Chilhood Education. New York: Guilford Press, 2012.

VICTORINO, L.C.O. Dossiê Leopoldo de Meis: Pesquisa, Divulgação Científica e Educação. 2019. Dissertação (Mestrado Profissional) - Educação, Gestão e Difusão Científica, Universidade Federal do Rio de Janeiro, Rio de Janeiro.

Recebido: 20 de setembro de 2019.

Aprovado: 21 de outubro de 2019. 
RUMJANEK, Vivian M.; DA-SILVA, Wagner S.

Ciência para todos?

RBPG, Brasília, v.15, n.34, 2019.

Artigo 